\title{
Metabolism of Aldosterone in Several Experimental Situations with Altered Aldosterone Secretion*
}

\author{
James O. Davis, $\dagger$ Michael J. Olichney, Torrey C. Brown, and Peter F. \\ Binnion $\ddagger$ With the surgical assistance of Alfred Casper \\ (From the Section on Experimental Cardiovascular Disease, Laboratory of Kidney and Electro- \\ lyte Metabolism, National Heart Institute, Bethesda, Md.)
}

In an earlier study (1), the rate of metabolism of aldosterone was found to be decreased in dogs with chronic passive congestion of the liver secondary to thoracic inferior vena caval constriction. After hepatectomy of these animals and of normal dogs, the metabolism of aldosterone was almost abolished. It was suggested that the decreased aldosterone metabolism during liver congestion might be secondary to decreased hepatic blood flow and associated hepatic anoxia. More recently, Tait and his colleagues $(2,3)$ have provided evidence that the rate of hepatic blood flow is one of the primary determinants of the rate of aldosterone metabolism.

The present observations were undertaken to examine the metabolism of aldosterone in several experimental situations in which altered aldosterone secretion occurs and in which there are known or suspected alterations in liver blood flow. The primary objectives were twofold: 1) to define the distribution, metabolic clearance rate (MCR), and hepatic extraction of aldosterone, and 2) to determine the contribution of altered aldosterone metabolism to the peripheral plasma level of aldosterone. Aldosterone metabolism was studied following acute hemorrhage, in dogs depleted of sodium, and in dogs with chronic experimental heart failure. Observations were made in both low and high output failure because hepatic blood flow is reduced in the former and, presumably, normal or elevated in the latter situation. Since exercise greatly reduces the blood flow through the liver in patients with heart failure (4), observations were made before and during ex-

* Submitted for publication January 4, 1965; accepted May 12, 1965.

$\dagger$ Address requests for reprints to Dr. James O. Davis, Building 3, Room 204, National Heart Institute, Bethesda, Md. 20014.

$\ddagger$ Ontario Heart Foundation research fellow. hausting exercise in dogs with low output heart failure. The metabolism of aldosterone was also studied in hypophysectomized dogs; in this situation there is a low rather than a high rate of aldosterone secretion, and hepatic blood flow is probably reduced. Finally, the hepatic extraction of aldosterone was measured in several experimental situations.

\section{Methods}

The rate of metabolism of aldosterone was studied by observing the rate of disappearance of $1,2-\mathrm{H}^{3}-d$-aldosterone from peripheral plasma; single iv injections of $12 \times 10^{6} \mathrm{cpm}$ of $1,2-\mathrm{H}^{3}-d$-aldosterone with a SA of 100 $\mu \mathrm{c}$ per $\mu \mathrm{g}$ were made. The efficiency of the liquid scintillation spectrometer was approximately $25 \%$. Peripheral venous blood samples of $20 \mathrm{ml}$ were drawn at $5,10,15$, $20,30,45,60,75$, and 90 minutes, and plasma was analyzed for true $\mathrm{H}^{3}$-d-aldosterone. The dogs weighed from 17 to $22 \mathrm{~kg}$.

To study the effects of hemorrhage, $30 \mathrm{ml}$ of arterial blood per $\mathrm{kg}$ body weight was removed over a 5- to 15minute period in nine dogs anesthetized with $\mathrm{Na}$ pentobarbital. As soon as the arterial pressure had stabilized, tritiated aldosterone was injected, and peripheral venous blood samples were obtained. Arterial pressure was measured continuously throughout the experiment by means of a Statham strain gauge and a Sanborn recording system. As a control experiment, the disappearance of tritiated aldosterone was studied in a series of seven normal dogs anesthetized similarly.

Sodium depletion was produced in seven normal dogs by feeding a diet containing less than $2 \mathrm{mEq}$ per day of $\mathrm{Na}$ and by administration of $2 \mathrm{ml}$ of Mercuhydrin intramuscularly on 4 successive days. The average negative $\mathrm{Na}$ balance for the 4 days in the group of seven dogs was $161 \mathrm{mEq}$. The disappearance of $\mathrm{H}^{3}$-d-aldosterone was studied in these conscious $\mathrm{Na}$-depleted animals, and the data were compared with results obtained in normal conscious dogs on a $\mathrm{Na}$ intake of $60 \mathrm{mEq}$ per day.

Chronic congestive heart failure of the low output type was produced by a combination of tricuspid insufficiency and pulmonic stenosis $(5,6)$. Pulmonic stenosis was achieved by an adjustable ligature that was placed around the main pulmonary artery and tightened under 
local anesthesia (6). All five animals showed evidence of right heart failure including an elevated venous pressure, tachycardia, hepatomegaly, almost complete renal $\mathrm{Na}$ retention, and ascites. In an earlier study (1) it was found that tritiated aldosterone equilibrated slowly between plasma and ascitic fluid. Therefore, for the present observations in experimental heart failure, ascites was removed as completely as possible immediately before injection of tritiated aldosterone. The disappearance of $\mathrm{H}^{3}$ - $d$-aldosterone was measured in resting conscious animals and again several days later during exhausting exercise. The dogs were run up 20 to 25 steps of stairs; venous pressure was measured before and during exercise in two of the three dogs.

High output heart failure was produced in two dogs by placing a large aortic-caval fistula about 1 inch below the kidneys (7). The animals were placed on daily $\mathrm{Na}$ balance studies and observed closely for signs of heart failure. At the onset of heart failure, $\mathrm{Na}$ retention was almost complete. Both animals died from heart failure and pulmonary edema within 3 days after the measurements of aldosterone metabolism were made. Pulmonary edema was evident by the large amount of frothy fluid that exuded from the trachea.

Hypophysectomy was performed by the oral approach, and the rate of metabolism of aldosterone was measured in four conscious animals after 6 weeks.

Extraction of aldosterone by the liver was determined by measuring the concentrations of $\mathrm{H}^{3}$ - $d$-aldosterone in peripheral and hepatic venous plasma. The first experiments were carried out in five dogs anesthetized with $\mathrm{Na}$ pentobarbital; the chest and abdomen were opened, and a catheter was passed from the external jugular vein into one of the hepatic veins. $\mathrm{H}^{3}$-d -aldosterone $\left(12 \times 10^{6} \mathrm{cpm}\right)$ was injected intravenously, and samples of blood were obtained simultaneously from a peripheral and a hepatic vein after 15, 20, and 30 minutes. Because of the rapid deterioration that occurred in these anesthetized animals with both the chest and abdomen open, hepatic extraction ratios were also measured in a group of eight conscious dogs. In these animals, a catheter was placed in a hepatic vein under sterile conditions several days before the experiment. It should be pointed out that this technique has certain advantages. The abdomen was opened, and a catheter was placed in one of the hepatic veins from the left lobe of the liver; the catheter tip was placed immediately beneath the surface of the most superficial hepatic vein in the region. Consequently, there was a substantial distance between the catheter tip and the inferior vena cava, and the possibility for reflux of blood was very small. Three additional dogs with chronic indwelling hepatic venous catheters were anesthetized before acute hemorrhage, and measurements of the hepatic extraction ratio of aldosterone were made under anesthesia.

The concentration of $\mathrm{H}^{3}$-d-aldosterone was measured in peripheral venous plasma by a slight modification (1) of the double isotope derivative assay (8), and two additional changes were made for the present study. First, the samples were run through a third chromatography; a cyclohexane (100 parts), benzene (50 parts), methanol
(100 parts), and water (25 parts) system was used, and the chromatogram was developed for 10 hours. Second, aldosterone-4-C ${ }^{14}$ was added directly to plasma rather than addition of aldosterone diacetate- $\mathrm{C}^{14}$ after acetylation as performed previously (1).

\section{Results}

Analysis of data. The data from the disappearance curves for $\mathrm{H}^{3}-d$-aldosterone for each of the groups of animals were averaged to yield a composite set of values (Figures 1 to 7 ). The values were plotted on semilogarithmic coordinate paper. Two exponential terms could be resolved for the disappearance curve from each group of animals. Accordingly, following tracer kinetic theory (9), a two compartmental model was proposed (1) to characterize the distribution and metabolism of aldosterone. The characteristics of a two compartmental model and the equations for calculation of the turnover rates and the volumes of distribution have been described previously (1). The data from a disappearance curve are not sufficient to permit solution of the values of all the $k_{i j}$ or turnover rates from the $j^{\text {th }}$ to the $i^{\text {th }}$ compartment. However, with certain assumptions about the $k_{1 j}$, it is possible to calculate all other turnover rates. Two reasonable assumptions were made and two models resulted: 1 ) $\mathrm{k}_{02}=0$, which means that losses or degradation of aldosterone take place from compartment 1 only (model I); and 2) $\mathrm{k}_{01}=0$, which requires that losses or degradation of aldosterone occur from compartment 2 only (model II).

Estimates of the volumes of distribution and turnover rates were made. The experimental values were plotted, and the disappearance curves were drawn by hand in an attempt to approximate ideal curves. From these curves, the $y$ intercepts $\left(a_{11}\right.$ and $\left.a_{12}\right)$ and the slopes $\left(\alpha_{1}\right.$ and $\left.\alpha_{2}\right)$ for the fast and slow components were calculated. By use of the equations that describe a two compartmental model (1), the rate constants were calculated for models I and II. The volume of distribution for compartment $I\left(S_{1}\right)$ is the same for both models. $S_{1}$ was calculated from the equation, $S_{1}=$ (total counts per minute injected $\times 100$ $\mathrm{ml}) /\left(\mathrm{a}_{11}+\mathrm{a}_{12}\right)$, and $\mathrm{S}_{2}=\left(\mathrm{k}_{21} \mathrm{~S}_{1}\right) / \mathrm{k}_{22}$, and $\mathrm{S}_{2}$ differs for each model because the $k_{i j}$ differ for models I and II.

The observed data from the disappearance 
curves were fitted to sums of exponentials by a least squares method with a digital computer program (10). The fitted values and the resultant data for $\mathrm{a}_{11}, \mathrm{a}_{12}, \alpha_{1}$, and $\alpha_{2}$ were obtained. By use of a digital computer, the initial estimates of $S_{1}, S_{2}$, and the fractional turnover rates were used to determine the definitive values and the standard errors for these functions. From the computer data for the volume of distribution and the turnover rate, the rate of plasma clearance in milliliters per minute or the MCR was calculated for each model. On the basis of tracer kinetic theory, the values for the MCR for each model should be equal.

From the available data, the assumed two compartmental model is acceptable to explain the metabolism of aldosterone in the situations studied. There are no systematic deviations between calculated and observed values for the plasma concentrations of aldosterone, and, in general, the standard errors of the volumes of distribution and the fractional turnover rates are small.

The results presented in Table I were obtained from the fitted data and computer analysis.

Effects of acute hemorrhage on the distribution and metabolism of aldosterone. Since acute hemorrhage of $30 \mathrm{ml}$ of blood per $\mathrm{kg}$ of body weight results in hypotension, blood pressure was recorded continuously throughout the experiment. The data show that a striking fall in arterial pressure occurred immediately following removal of blood (Figure 1). Within 30 minutes arterial pressure had increased, and a relatively stable

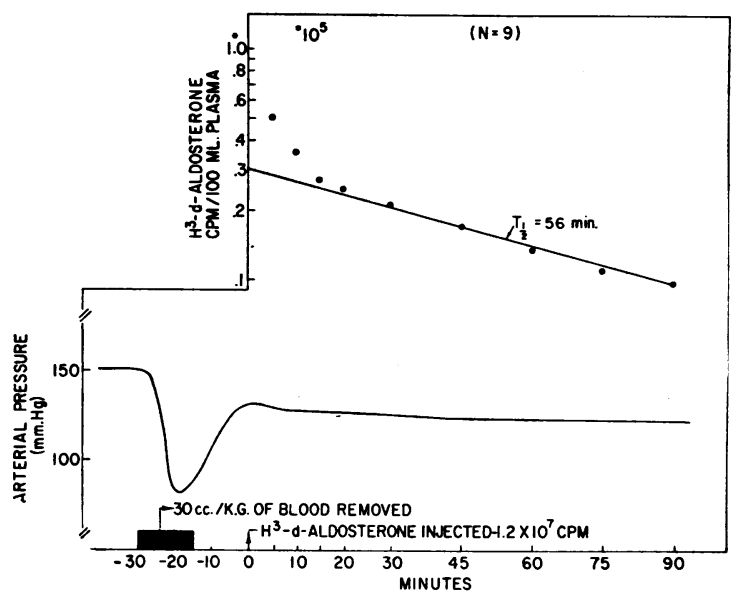

Fig. 1. Changes in mean femoral arterial pressure AND THE DISAPPEARANCE CURVE OF $\mathrm{H}^{3}$-D-ALDOSTERONE FOLLOWING ACUTE HEMORRHAGE OF ANESTHETIZED DOGS.

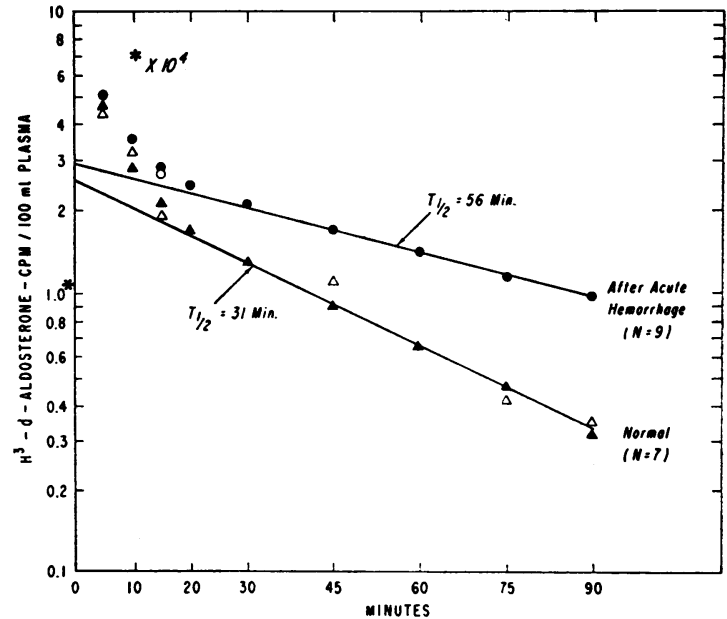

Fig. 2. Disappearance curves of $\mathrm{H}^{3}$-d-Aldosterone IN NORMAL ANESTHETIZED DOGS AND IN DOGS SUBJECTED TO ACUTE HEMORRHAGE. Open symbols represent experimental values; solid symbols are fitted data. Where only solid symbols are plotted, the experimental and fitted data coincide.

state was achieved. Thereafter, only a slight progressive decline in arterial pressure occurred. The disappearance curve for $\mathrm{H}^{3}$ - $d$-aldosterone is presented in the upper part of Figure 1 to show its relationship to blood pressure. There are two exponential components to the disappearance curve, and the findings give no indication that an unstable state was present.

The disappearance curves for $\mathrm{H}^{3}$ - $d$-aldosterone in normal, anesthetized dogs and in the anesthetized, acutely bled animals are presented in Figure 2. The slow component of the disappearance curve is considerably more flat in the animals subjected to hemorrhage than in the normal dogs. The biological half-life $\left(t_{i}\right)$ of aldosterone from the slow component is longer ( 56 minutes) for the hemorrhaged than for the normal dogs (31 minutes). Neither $S_{1}$ nor $S_{2}$ was altered appreciably by hemorrhage (see comparison between normal anesthetized and bled dogs in Table I), but the fractional turnover rates $\left(k_{01}\right.$ for model $I$ and $k_{02}$ for model II) were decreased (Table I). The metabolic clearance rate was reduced $45 \%$ by hemorrhage. Studies of hepatic extraction of aldosterone demonstrated that extraction was almost complete in both normal and bled dogs, and no difference between the two groups was discernible (Table II). Hepatic extraction ratios of $100 \%$ represent he- 


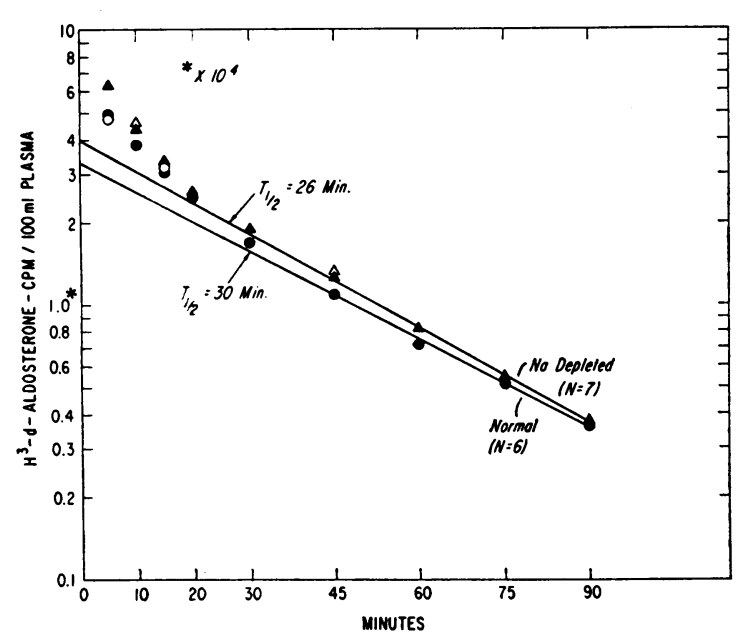

Fig. 3. Disappearance curves of $\mathrm{H}^{3}$-D-Aldosterone FOR NORMAL CONSCIOUS DOGS AND CONSCIOUS NA-DEPLETED Dogs. Net $\mathrm{Na}$ loss was $161 \mathrm{mEq}$. See Figure 2 for symbols.

patic vein samples in which the counts per minute per milliliter were not above the background counts.

Aldosterone metabolism and distribution in sodium-depleted dogs. The disappearance curves of
$\mathrm{H}^{3}$ - $d$-aldosterone for the group of $\mathrm{Na}$-depleted dogs and a group of normal conscious animals are presented in Figure 3. The two curves are indistinguishable. The $t_{t}$ of the slow component is 30 minutes for the normal dogs and 26 minutes for the Na-depleted dogs. It is of interest that the curve for the normal conscious dogs is almost identical to that observed earlier (1) for another group of normal conscious animals in which the $\mathrm{t}_{1}$ was 27 minutes.

Analysis of the data in terms of a two compartmental model revealed a $41 \%$ drop in the volume of distribution $\left(\mathrm{S}_{1}\right)$ of compartment 1 and a fall of $35 \%$ for $\mathrm{S}_{2}$ (Table I). Thus, the fractional turnover rates $k_{01}$ and $k_{02}$ were increased, but the metabolic clearance rate of aldosterone was not significantly altered by $\mathrm{Na}$ depletion.

The hepatic extraction ratios for aldosterone ranged from 80 to $98 \%$ for the anesthetized $\mathrm{Na}$ depleted dogs and from 88 to $100 \%$ for conscious Na-depleted animals (Table II). These values were essentially the same as the normal extraction ratios.

Distribution and metabolism of aldosterone in

TABLE I

Distribution and metabolism of $H^{3}$-d-aldosterone*

\begin{tabular}{|c|c|c|c|c|c|c|c|}
\hline \multirow[b]{2}{*}{ Dogs } & \multicolumn{3}{|c|}{ Model I } & \multicolumn{3}{|c|}{ Model II } & \multirow[b]{2}{*}{$t_{1}$} \\
\hline & $\mathrm{S}_{1}$ & $\mathbf{k}_{01}$ & MCR & $S_{2}$ & $k_{02}$ & MCR & \\
\hline & $L$ & $\begin{array}{l}\text { fraction of } \\
\text { pool } / \mathrm{min}\end{array}$ & $\mathrm{ml} / \mathrm{min}$ & $L$ & $\begin{array}{l}\text { fraction of } \\
\text { pool } / \mathrm{min}\end{array}$ & $m l / m i n$ & $\min$ \\
\hline Normal (conscious) & $\begin{array}{l}18.67 \\
\pm 0.89 \dagger\end{array}$ & $\begin{array}{r}0.0385 \\
\pm 0.0018\end{array}$ & 718 & $\begin{array}{r}23.59 \\
\pm 3.94\end{array}$ & $\begin{array}{r}0.0304 \\
\pm 0.0050\end{array}$ & 717 & 30 \\
\hline Normal (anesthetized) & $\begin{array}{r}12.31 \\
\pm 4.61\end{array}$ & $\begin{array}{r}0.0676 \\
\pm 0.0179\end{array}$ & 832 & $\begin{array}{r}27.38 \\
\pm 3.18\end{array}$ & $\begin{array}{r}0.0304 \\
\pm 0.0035\end{array}$ & 832 & 31 \\
\hline $\begin{array}{l}\text { After acute blood loss } \\
\quad \text { (anesthetized) }\end{array}$ & $\begin{array}{r}13.02 \\
\pm 1.47\end{array}$ & $\begin{array}{r}0.0348 \\
\pm 0.0039\end{array}$ & 453 & $\begin{array}{r}24.04 \\
\pm 1.44\end{array}$ & $\begin{array}{r}0.0188 \\
\pm 0.0011\end{array}$ & 451 & 56 \\
\hline Sodium depleted (conscious) & $\begin{array}{r}10.98 \\
\pm 1.67\end{array}$ & $\begin{array}{r}0.0567 \\
\pm 0.0080\end{array}$ & 622 & $\begin{array}{r}15.37 \\
\pm 1.20\end{array}$ & $\begin{array}{r}0.0405 \\
\pm 0.0029\end{array}$ & 622 & 26 \\
\hline $\begin{array}{l}\text { Low output heart failure } \\
\text { (conscious) }\end{array}$ & $\begin{array}{r}12.15 \\
\pm 2.04\end{array}$ & $\begin{array}{r}0.0266 \\
\pm 0.0072\end{array}$ & 323 & $\begin{array}{r}26.26 \\
\pm 12.31\end{array}$ & $\begin{array}{r}0.0123 \\
\pm 0.0058\end{array}$ & 322 & 68 \\
\hline $\begin{array}{l}\text { High output heart failure } \\
\text { (conscious) }\end{array}$ & $\begin{array}{r}6.96 \\
\pm 2.29\end{array}$ & $\begin{array}{r}0.1019 \\
\pm 0.0311\end{array}$ & 709 & $\begin{array}{r}24.79 \\
\pm 1.42\end{array}$ & $\begin{array}{r}0.0282 \\
\pm 0.0016\end{array}$ & 699 & 31 \\
\hline $\begin{array}{l}\text { Hypophysectomized group I } \\
\text { (conscious) }\end{array}$ & $\begin{array}{r}10.84 \\
\pm 2.05\end{array}$ & $\begin{array}{r}0.0361 \\
\pm 0.0080\end{array}$ & 391 & $\begin{array}{r}26.24 \\
\pm 8.71\end{array}$ & $\begin{array}{r}0.0149 \\
\pm 0.0049\end{array}$ & 390 & 60 \\
\hline $\begin{array}{l}\text { Hypophysectomized group II } \\
\text { (conscious) }\end{array}$ & $\begin{array}{r}12.31 \\
\pm 1.34\end{array}$ & $\begin{array}{r}0.0437 \\
\pm 0.0060\end{array}$ & 537 & $\begin{array}{r}33.23 \\
\pm 9.13\end{array}$ & $\begin{array}{r}0.0163 \\
\pm 0.0045\end{array}$ & 451 & 44 \\
\hline
\end{tabular}

$* S_{1}$ and $S_{2}=$ volume of distribution for the two compartments; $k_{01}$ and $k_{02}=$ turnover rates; MCR = metabolic clearance rate.

† Standard error. 
TABLE II

Hepatic extraction ratio of $H^{3}$-d-aldosterone in dogs*

\begin{tabular}{|c|c|c|c|c|}
\hline $\begin{array}{l}\text { Type of } \\
\text { animals }\end{array}$ & $\begin{array}{l}\text { Dog } \\
\text { no. }\end{array}$ & $\underset{\min }{\text { After } 15}$ & $\underset{\min }{\text { After }} 20$ & $\begin{array}{c}\text { After } 30 \\
\min \end{array}$ \\
\hline & & $\begin{array}{c}\% \text { Ex- } \\
\text { traction } \\
\text { Anesthetized }\end{array}$ & $\underset{\text { traction }}{\% E x-}$ & $\underset{\text { traction }}{\text { \% Ex- }}$ \\
\hline Normal & $\begin{array}{l}1 \\
2\end{array}$ & $\begin{array}{l}93 \\
87\end{array}$ & & $\begin{array}{l}95 \\
81\end{array}$ \\
\hline $\begin{array}{l}\text { After acute } \\
\text { blood loss }\end{array}$ & $\begin{array}{l}1 \\
2 \\
3\end{array}$ & $\begin{array}{r}97 \\
93 \\
100\end{array}$ & $\begin{array}{r}84 \\
100\end{array}$ & $\begin{array}{r}100 \\
94 \\
96\end{array}$ \\
\hline $\begin{array}{l}\text { Sodium } \\
\text { depleted }\end{array}$ & $\begin{array}{l}1 \\
2\end{array}$ & $\begin{array}{l}98 \\
93\end{array}$ & $\begin{array}{l}85 \\
86\end{array}$ & $\begin{array}{l}98 \\
80\end{array}$ \\
\hline \multirow[t]{2}{*}{$\begin{array}{l}\text { Thoracic } \\
\text { caval } \\
\text { constriction }\end{array}$} & 1 & 87 & 94 & 95 \\
\hline & & Conscious & & \\
\hline Normal & $\begin{array}{l}1 \\
2 \\
3\end{array}$ & $\begin{array}{r}99 \\
100 \\
96\end{array}$ & $\begin{array}{r}100 \\
90 \\
98\end{array}$ & $\begin{array}{r}86 \\
85 \\
100\end{array}$ \\
\hline $\begin{array}{l}\text { Sodium } \\
\text { depleted }\end{array}$ & $\begin{array}{l}1 \\
2\end{array}$ & $\begin{array}{l}99 \\
88\end{array}$ & $\begin{array}{l}100 \\
100\end{array}$ & $\begin{array}{r}98 \\
100\end{array}$ \\
\hline $\begin{array}{l}\text { Thoracic } \\
\text { caval } \\
\text { constriction }\end{array}$ & $\frac{1}{2}$ & $\begin{array}{l}100 \\
100\end{array}$ & $\begin{array}{l}100 \\
100\end{array}$ & \\
\hline $\begin{array}{l}\text { Hypophy- } \\
\text { sectomized }\end{array}$ & 1 & 100 & 100 & 100 \\
\hline
\end{tabular}

* Simultaneous hepatic and peripheral venous blood samples were drawn at 15,20 , and 30 minutes after a single injection of $12 \times 10^{6} \mathrm{cpm}$ of $\mathrm{H}^{3}-d$-aldosterone, and plasma was analyzed for true $\mathrm{H}^{3}-d$-aldosterone.

chronic experimental heart failure. The disappearance curve of $\mathrm{H}^{3}$-d-aldosterone for dogs with low output heart failure is presented for comparison with the normal curve (Figure 4 ). The $t_{1}$ for the slow component of the curve from the dogs with heart failure is 68 minutes, which represents a marked prolongation over the normal $t_{3}$ of 30 minutes. The volume of distribution $\mathrm{S}_{1}$ was reduced $35 \%$ in the heart failure dogs, whereas $S_{2}$ was unchanged (Table $I$ ). The fractional turnover rates $k_{01}$ and $k_{02}$ were reduced, and since $S_{2}$ was unaltered the reduction in $k_{02}$ was much greater than that for $\mathrm{k}_{01}$ (Table I). The metabolic clearance rate was decreased from 718 to $322 \mathrm{ml}$ per minute, a $55 \%$ fall (Table I).

Since exercise has been found to decrease hepatic blood flow markedly in patients with heart failure (4), three of the dogs with low output heart failure were subjected to exhausting exercise (Figure 5). The venous pressure, which ranged from 180 to $190 \mathrm{~mm}$ water before exercise, increased to 205 to $300 \mathrm{~mm}$ water during exercise. All three animals were tachypneic and showed signs of weakness and exhaustion during exercise. The disappearance curves of $\mathrm{H}^{3}-d$-aldosterone,

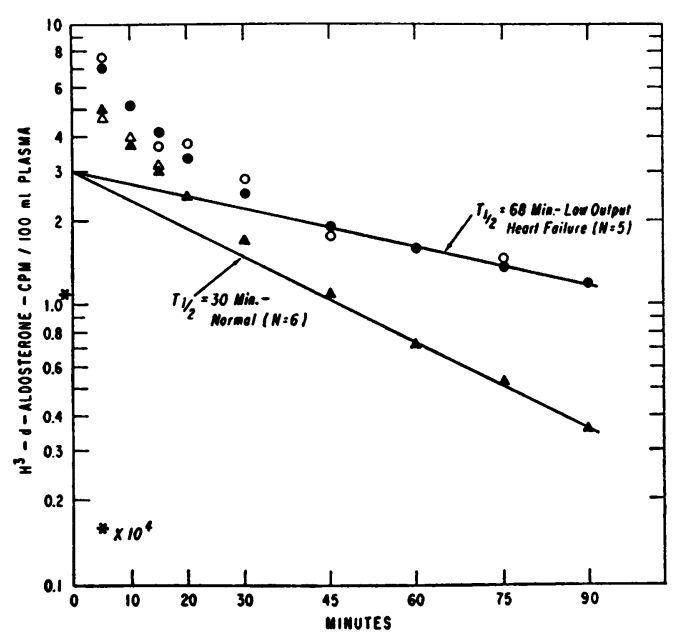

Fig. 4. Disappearance curves for $\mathrm{H}^{3}$-D-Aldosterone IN NORMAL CONSCIOUS DOGS AND IN DOGS WITH EXPERIMENTAL LOW OUTPUT heART FaILURE. See Figure 2 for symbols.

although obtained several days apart, were essentially the same before and during exercise. The slow component of the curve was very flat, and the long $t_{1}$ of 71 minutes before exercise was not altered significantly. Calculations showed that the metabolic clearance rate of aldosterone was not detectably influenced by exercise.

In two dogs with high output failure secondary to a large aortic-caval fistula, the disappearance curve was within normal limits (Figure 6). The

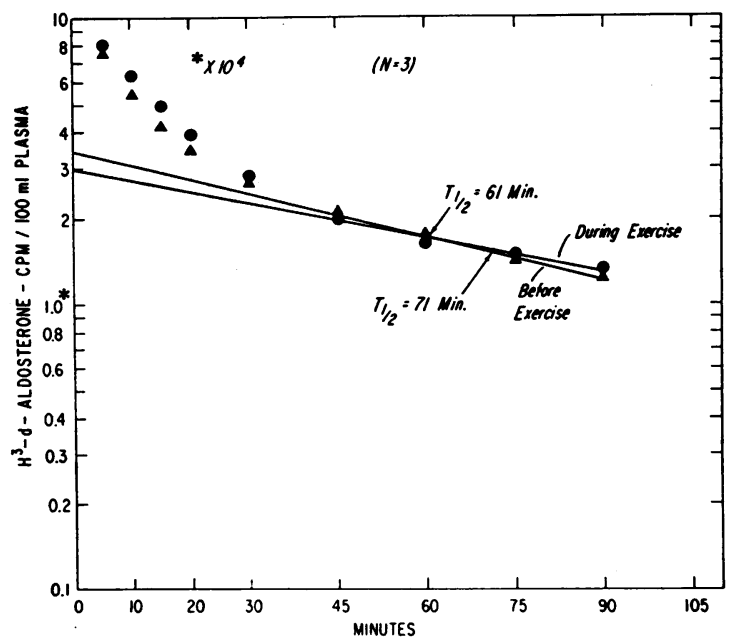

Fig. 5. FaIlure of Exercise to alter the rate of DISAPPEARANCE OF $\mathrm{H}^{3}$-D-ALDOSTERONE IN THREE DOGS WITH EXPERIMENTAL LOW OUTPUT HEART FAILURE. 
$t_{1}$ of the slow component was 31 minutes in comparison with the $t_{3}$ of 30 minutes for normal conscious dogs. Consequently, the MCR for dogs with high output failure was not appreciably different from the normal MCR (Table I). The volume of distribution for compartment $1\left(\mathrm{~S}_{1}\right)$ was markedly reduced, but $S_{2}$ was not significantly changed. Thus, $k_{01}$ was very high, whereas $k_{02}$ was unaltered.

To evaluate the influence of chronic passive congestion of the liver on the hepatic extraction of aldosterone, hepatic extraction ratios were obtained in dogs with chronic constriction of the thoracic inferior vena cava (1). Hepatic extraction of aldosterone in these animals was virtually complete despite the marked liver congestion (Table II). This result is in contrast to the frequent finding of a decreased hepatic extraction ratio of aldosterone in patients with heart failure $(3,11,12)$. The difference in the extraction of aldosterone by the liver in man and in the experimental animal with heart failure may be a reflection of more severe liver damage in man because of the longer duration of the disease.

Aldosterone metabolism and distribution in hypophysectomized dogs. The data from the hypophysectomized dogs have been divided into two groups on the basis of the completeness of hypophysectomy. In group I (two dogs), hypophysectomy was complete or almost complete as indicated

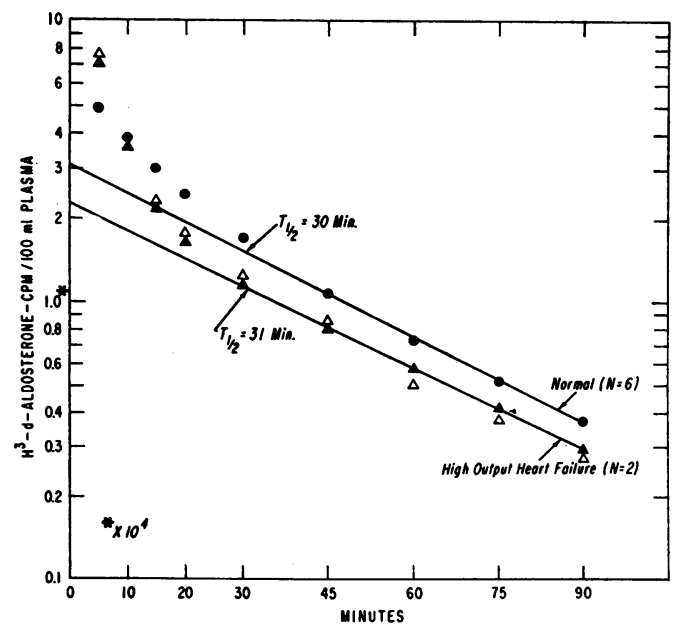

Fig. 6. Disappearance CURVES FOR $\mathrm{H}^{8}$-D-ALDOSTERONE IN NORMAL CONSCIOUS DOGS AND IN DOGS WITH HIGH OUTPUT HEART FAILURE SECONDARY TO AN AORTIC-CAVAL FISTULA.

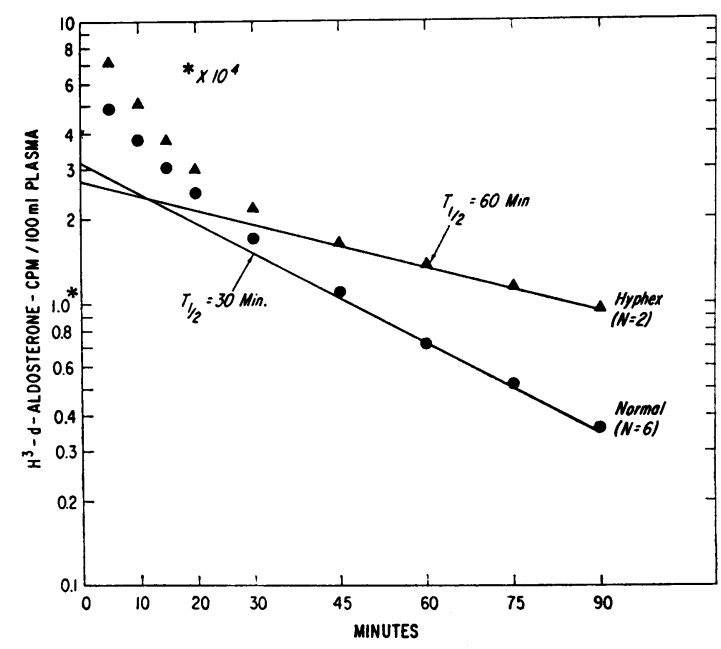

Fig. 7. Disappearance curves fOR $\mathrm{H}^{3}$-D-ALDOSTERone IN NORMAL CONSCIOUS DOGS AND IN DOGS 6 WEEKS AFTER HYPOPHYSECTOMY.

by markedly atrophic adrenals; the left adrenals weighed 0.43 and $0.45 \mathrm{~g}$ for the two animals, whereas the left adrenals from normal dogs of the same size weighed $0.81 \pm 0.04 \mathrm{~g} \mathrm{SE}(\mathrm{N}=17)$. In two other animals (group II), the adrenals were only partially atrophied; the left adrenals weighed 0.56 and $0.62 \mathrm{~g}$. The $t_{1}$ of the slow component of the disappearance curve from the group I dogs was 60 (Figure 7), whereas the $t_{1}$ was 44 minutes for the group II dogs (Table I). $\mathrm{S}_{1}$ was reduced $42 \%$ for group I dogs and $34 \%$ for group II animals (Table I); $S_{2}$ was not significantly altered in either group of dogs. $k_{01}$ was unaltered in either group, but $k_{02}$ was markedly decreased in both the completely and incompletely hypophysectomized animals. The MCR was decreased $46 \%$ in group I and $25 \%$ in group II. The hepatic extraction of aldosterone was measured in one of the hypophysectomized dogs of group II (Table II), and extraction was complete.

\section{Discussion}

In the present study, the single injection method was used to measure the metabolism of aldosterone. This procedure has the advantage over the constant infusion method in that more information can be obtained. Not only can the rate of disappearance or metabolism of aldosterone be ascertained, but the volume of distribution and the fractional turnover rate can be calculated. The rate 
of clearance of aldosterone from peripheral plasma in milliliters per minute, the MCR, can be calculated by multiplying the volume of distribution by the fractional turnover rate. Tait and his colleagues (2) have demonstrated by the single injection and constant infusion methods that the MCR for normal human subjects is essentially the same (within 10\%). In general, the present data show an inverse correlation between the $t_{i}$ of the slow component of the disappearance curves and the MCR (Table I). However, when the volume of distribution was altered markedly as during $\mathrm{Na}$ depletion, this relationship was not close.

After acute hemorrhage there was a marked reduction in the rate of metabolism of aldosterone. Consequently, after acute blood loss decreased metabolism as well as increased secretion of aldosterone leads to an elevation of the peripheral plasma level. Actual calculations of the peripheral plasma concentration of aldosterone from known secretion rate values in anesthetized dogs (13) and the present data on plasma clearance in anesthetized animals show that hemorrhage increased the peripheral plasma level of aldosterone from 0.005 to $0.0175 \mu \mathrm{g}$ per $100 \mathrm{ml}$. The present data demonstrate, therefore, the occurrence of another important mechanism leading to hyperaldosteronemia that promotes the retention of salt and water following acute hemorrhage. Both the renin-angiotensin system and ACTH lead to increased aldosterone secretion after blood loss (14), and acute hemorrhage is one of the most potent stimuli for release of antidiuretic hormone and water conservation (15).

The degree of $\mathrm{Na}$ depletion used in this study failed to produce a detectable alteration in aldosterone metabolism. However, the volume of distribution was markedly decreased, a finding that may reflect a decreased plasma and extracellular fluid volume. Net $\mathrm{Na}$ loss was $161 \mathrm{mEq}$ over the 4 days. This same $\mathrm{Na}$ depletion regimen with a similar loss of $\mathrm{Na}$ produced a $200 \%$ increase in aldosterone secretion in conscious dogs (16). Available data demonstrate, therefore, that increased secretion is the primary mechanism leading to hyperaldosteronemia during this degree of $\mathrm{Na}$ depletion. Calculations of the peripheral plasma concentration of aldosterone show an increase from the value of $0.002 \mu \mathrm{g}$ per $100 \mathrm{ml}$ for normal conscious dogs to $0.025 \mu \mathrm{g}$ per $100 \mathrm{ml}$ during $\mathrm{Na}$ depletion in conscious animals.

In chronic low output experimental heart failure, both the volume of distribution and the fractional turnover rate were reduced. The result was a decrease in metabolic clearance rate of $55 \%$, and the $t_{\frac{1}{2}}$ for the slow component of the disappearance curve was the longest observed in these several experimental situations. Calculations of the peripheral plasma level of aldosterone from known values for aldosterone secretion and the present MCR data show an increase from 0.002 to $0.088 \mu \mathrm{g}$ per $100 \mathrm{ml}$. The explanation for the decreased volume of distribution is not clear. Failure of exercise to decrease further the rate of metabolism of aldosterone is probably a reflection of the slow rate of degradation before exercise. It seems likely that hepatic blood flow was very low in these animals with heart failure and that a further decrease failed to occur; the resting MCR of aldosterone for the animals before exercise was the lowest observed in the several situations studied. These findings during the resting state in chronic experimental low output failure agree with the results on the metabolism of aldosterone in patients with heart failure $(3,11,12,17$, 18 ) in that MCR was reduced. No data are available on the effect of exercise on aldosterone metabolism in patients with cardiac failure, and the measurements of hepatic blood flow in patients were made (4) on individuals with less heart failure than these experimental animals. Since the MCR of aldosterone is unchanged in experimental high output failure, the increase in the peripheral plasma level of aldosterone is the result of increased secretion of the hormone (7).

After hypophysectomy, the decrease in MCR might be considered to provide a compensatory mechanism to help maintain the peripheral plasma level of aldosterone in the presence of decreased aldosterone secretion. However, in spite of this mechanism the peripheral plasma level of aldosterone was reduced because of the relatively more marked reduction in secretion than in MCR.

A decrease in hepatic blood flow appears to be the primary mechanism leading to decreased aldosterone metabolism. Since the slow component of the disappearance curve for aldosterone is almost flat following hepatectomy (1), the liver is the principal site for metabolism of aldosterone. The 
present data on the almost complete hepatic extraction of aldosterone and the earlier evidence (1) for negligible extrahepatic clearance of aldosterone from plasma indicate that the system for the metabolism of aldosterone is flow-limited. In other words, with complete extraction of aldosterone in one circulation of blood through the liver, a decrease in the total amount of aldosterone extracted by the liver per unit of time is effected by a decrease in hepatic blood flow.

The importance of hepatic blood flow in determining the rate of metabolism of aldosterone is also indicated by the frequent association of reduced liver blood flow with decreased MCR for aldosterone. Smythe (19) has reported a drop in hepatic blood flow from 43.4 to $20.8 \mathrm{ml}$ per $\mathrm{kg}$ per minute following removal of $33 \mathrm{ml}$ of blood per $\mathrm{kg}$ of body weight in anesthetized dogs. The authors are unaware of measurements of hepatic blood flow during $\mathrm{Na}$ depletion; if hepatic blood flow was decreased in the present study, the change was inadequate to influence aldosterone metabolism. There are many studies that demonstrate decreased hepatic blood flow in patients with low output heart failure $(4,20)$, and the MCR for aldosterone is markedly reduced in both patients and experimental animals with this type of cardiac failure. In high output failure, data are not available on the rate of hepatic blood flow. After hypophysectomy, a marked decrease (50 to $70 \%$ ) in cardiac output occurs (21), and on this basis hepatic blood flow might be expected to be low. Measurements of hepatic blood flow (personal observations) in one of the four hypophysectomized animals of this study revealed a reduction in liver blood flow, and the MCR for aldosterone was reduced by hypophysectomy. Thus, the present alterations in aldosterone metabolism parallel the known or suspected changes in hepatic blood flow. In support of this relationship, Bougas and associates (3) have recently demonstrated that the MCR for aldosterone was halved by a change from the supine to the upright posture in man; hepatic blood flow also fell approximately 50\% with this change in position (22).

Finally, it should be pointed out that decreased aldosterone metabolism is not always associated with increased aldosterone secretion. The exception in this study is the occurrence of a decreased MCR in the hypophysectomized dog in which al- dosterone secretion is markedly reduced (13). Usually, however, altered cardiovascular hemodynamic function with reductions in both renal and hepatic blood flow leads to hyperaldosteronemia by the dual mechanism of hypersecretion and decreased metabolism of aldosterone. A negative feedback mechanism has been proposed $(14,16)$ to explain the regulation of aldosterone secretion and the peripheral plasma concentration of aldosterone.

\section{Summary}

The rate of disappearance of $\mathrm{H}^{3}-d$-aldosterone from peripheral plasma was studied in dogs. The data were analyzed in terms of a two compartmental model; the volume of distribution, fractional turnover rate, and metabolic clearance rate (MCR) were calculated. The $t_{\frac{1}{1}}$ of the slow component of the disappearance curve was prolonged and the MCR was decreased after hemorrhage, following hypophysectomy, and in experimental low output heart failure, but aldosterone metabolism was not detectably altered during $\mathrm{Na}$ depletion or in high output heart failure. Consequently, a decreased rate of aldosterone metabolism contributed to the hyperaldosteronemia of hemorrhage and experimental low output heart failure and provided a mechanism for counteracting the low secretion rate of aldosterone in experimental hypopituitarism. Exhaustive exercise in dogs with low output heart failure failed to produce a further decrease in the low rate of aldosterone metabolism. An inverse relationship was observed between the $t_{\frac{1}{2}}$ of the slow component of the disappearance curves and the MCR.

Measurements of the hepatic extraction of aldosterone demonstrated almost complete removal of the hormone in one circulation of blood through the liver in normal dogs, following acute blood loss, during $\mathrm{Na}$ depletion, after hypophysectomy, and during severe congestion of the liver secondary to thoracic caval constriction. This finding suggests that the hepatic mechanism for metabolism of aldosterone is flow-limited, since previous study has indicated negligible extrahepatic clearance of aldosterone from plasma. Also, there is evidence that hepatic blood flow is decreased in the present conditions with a low rate of aldosterone metabolism. 


\section{Acknowledgments}

We are grateful to Dr. Mones Berman for his helpful advice in the use of the digital computer program.

\section{References}

1. Ayers, C. R., J. O. Davis, F. Lieberman, C. C. J. Carpenter, and M. Berman. The effects of chronic hepatic venous congestion on the metabolism of $d, l$-aldosterone and $d$-aldosterone. $\mathrm{J}$. clin. Invest. 1962, 41, 884.

2. Tait, J. F., B. Little, S. A. S. Tait, and C. Flood. The metabolic clearance rate of aldosterone in pregnant and nonpregnant subjects estimated by both single-injection and constant-infusion methods. J. clin. Invest. 1962, 41, 2093.

3. Bougas, J., C. Flood, B. Little, J. F. Tait, S. A. S. Tait, and R. Underwood. Dynamic aspects of aldosterone metabolism in Symposium on Aldosterone. Oxford, Blackwell, 1964, p. 25.

4. Donald, K. W. Hemodynamics in chronic congestive heart failure. J. chron. Dis. 1959, 9, 476.

5. Barger, A. C., B. B. Roe, and G. S. Richardson. Relation of valvular lesions and of exercise to auricular pressure, work tolerance, and to development of chronic, congestive failure in dogs. Amer. J. Physiol. 1952, 169, 384.

6. Yankopoulos, N. A., J. O. Davis, J. A. McFarland, and J. Holman. Physiologic changes during chronic congestive heart failure in dogs with tricuspid insufficiency and pulmonic stenosis. $\mathrm{Cir}$ culat. Res. 1959, 7, 950.

7. Davis, J. O., J. Urquhart, J. T. Higgins, Jr., E. C. Rubin, and P. M. Hartroft. Hypersecretion of aldosterone in dogs with a chronic aortic-caval fistula and high output heart failure. Circulat. Res. 1964, 14, 471.

8. Kliman, B., and R. E. Peterson. Double isotope derivative assay of aldosterone in biological extracts. J. biol. Chem. 1960, 235, 1639.

9. Berman, M., and R. Schoenfeld. Invariants in experimental data in linear kinetics and the formulation of models. J. appl. Physics 1956, 27, 1361.

10. Berman, M., E. Shahn, and M. Weiss. The routine fitting of kinetics data to models: a mathematical formation for digital computers. Biophys. J. 1962, 2, 275.

11. Camargo, C. A., A. J. Dowdy, E. W. Hancock, and J. A. Luetscher. Decreased plasma clearance and hepatic extraction of aldosterone in patients with heart failure. J. clin. Invest. 1965, 44, 356.

12. Tait, J. F., J. Bougas, B. Little, S. A. S. Tait, and C. Flood. Splanchnic extraction and clearance of aldosterone in subjects with minimal and marked cardiac dysfunction. J. clin. Endocr. 1965, 25, 219.

13. Davis, J. O., C. C. J. Carpenter, C. R. Ayers, J. E. Holman, and R. C. Bahn. Evidence for secretion of an aldosterone-stimulating hormone by the kidney. J. clin. Invest. 1961, 40, 684.

14. Davis, J. O. The control of aldosterone secretion. Physiologist 1962, 5, No. 2, 65.

15. Tepperman, J. The hypothalamo-hypophysial relay systems in Metabolic and Endocrine Physiology. Chicago, Year Book, 1962.

16. Binnion, P. F., J. O. Davis, T. C. Brown, and M. J. Olichney. Mechanisms regulating aldosterone secretion during sodium depletion. Amer. J. Physiol. 1965, 208, 655.

17. Luetscher, J. A., C. A. Camargo, A. P. Cohn, A. J. Dowdy, and A. M. Callaghan. Observations on metabolism of aldosterone in man. Ann. intern. Med. 1963, 59, 1.

18. Wolff, H. P., D. Lommer, J. Jahnecke, and M. Torbica. Hyperaldosteronism in edema in Symposium on Aldosterone. Oxford, Blackwell, 1964, p. 471.

19. Smythe, C. McC. Effect of hemorrhage on hepatic blood flow determined by radioactive colloidal chromic phosphate removal. Circulat. Res. 1959, 7, 268.

20. Davis, J. O. The physiology of congestive heart failure in Circulation Handbook. 1965, vol. 3, in press.

21. Goodkind, M. J., J. O. Davis, W. C. Ball, Jr., and R. C. Bahn. Alterations in cardiovascular and renal hemodynamic function following hypophysectomy in the dog. Amer. J. Physiol. 1957, 188, 529.

22. Culbertson, J. W., R. W. Wilkins, F. J. Ingelfinger, and S. E. Bradley. The effect of upright position upon hepatic blood flow in normotensive and hypertensive subjects. J. clin. Invest. 1951, 30, 305.

\section{SPECIAL NOTICE TO SUBSCRIBERS}

Post Offices will no longer forward the Journal when you move.

Please notify The Journal of Clinical Investigation, Business Office, 10 Stoughton Street, Boston, Mass. 02118, at once when you have a change of address, and do not omit the Zip Code number. 